Review

\title{
Update on Insomnia after Mild Traumatic Brain Injury
}

\author{
Yi Zhou ${ }^{1}$ and Brian D. Greenwald ${ }^{2, *}$
}

1 Rutgers Robert Wood Johnson Medical School, Piscataway, NJ 08854, USA; yz411@scarletmail.rutgers.edu

2 JFK Johnson Rehabilitation Institute, Edison, NJ 08820, USA

* Correspondence: brian.greenwald@hackensackmeridian.org

Received: 18 November 2018; Accepted: 11 December 2018; Published: 13 December 2018

\begin{abstract}
Sleep disturbance after traumatic brain injury (TBI) has received growing interest in recent years, garnering many publications. Insomnia is highly prevalent within the mild traumatic brain injury (mTBI) population and is a subtle, frequently persistent complaint that often goes undiagnosed. For individuals with mTBI, problems with sleep can compromise the recovery process and impede social reintegration. This article updates the evidence on etiology, epidemiology, prognosis, consequences, differential diagnosis, and treatment of insomnia in the context of mild TBI. This article aims to increase awareness about insomnia following mTBI in the hopes that it may improve diagnosis, evaluation, and treatment of sleeping disturbance in this population while revealing areas for future research.
\end{abstract}

Keywords: mild traumatic brain injury; mTBI; concussion; insomnia; sleep disturbance; treatment

\section{Methods}

References for this narrative review were obtained using a search of online databases PUBMED, MEDLINE, CINAL, and COCHRANE (Figure 1). These online databases were used to search for papers published after the year 2000 using keywords: mild traumatic brain injury, mTBI, concussion, insomnia, sleep disturbance, and treatment. Boolean operator "AND" was used to connect search terms and narrow results. Truncations and $\mathrm{MeSH}$ headings were not used. Some references were not identified using the online databases, but were obtained through reference lists of other articles. Our inclusion criteria were studies that looked primarily at brain injury cases, specifically mild traumatic brain injury. Only papers printed in or translated into English were included. We excluded case reports as sources. 


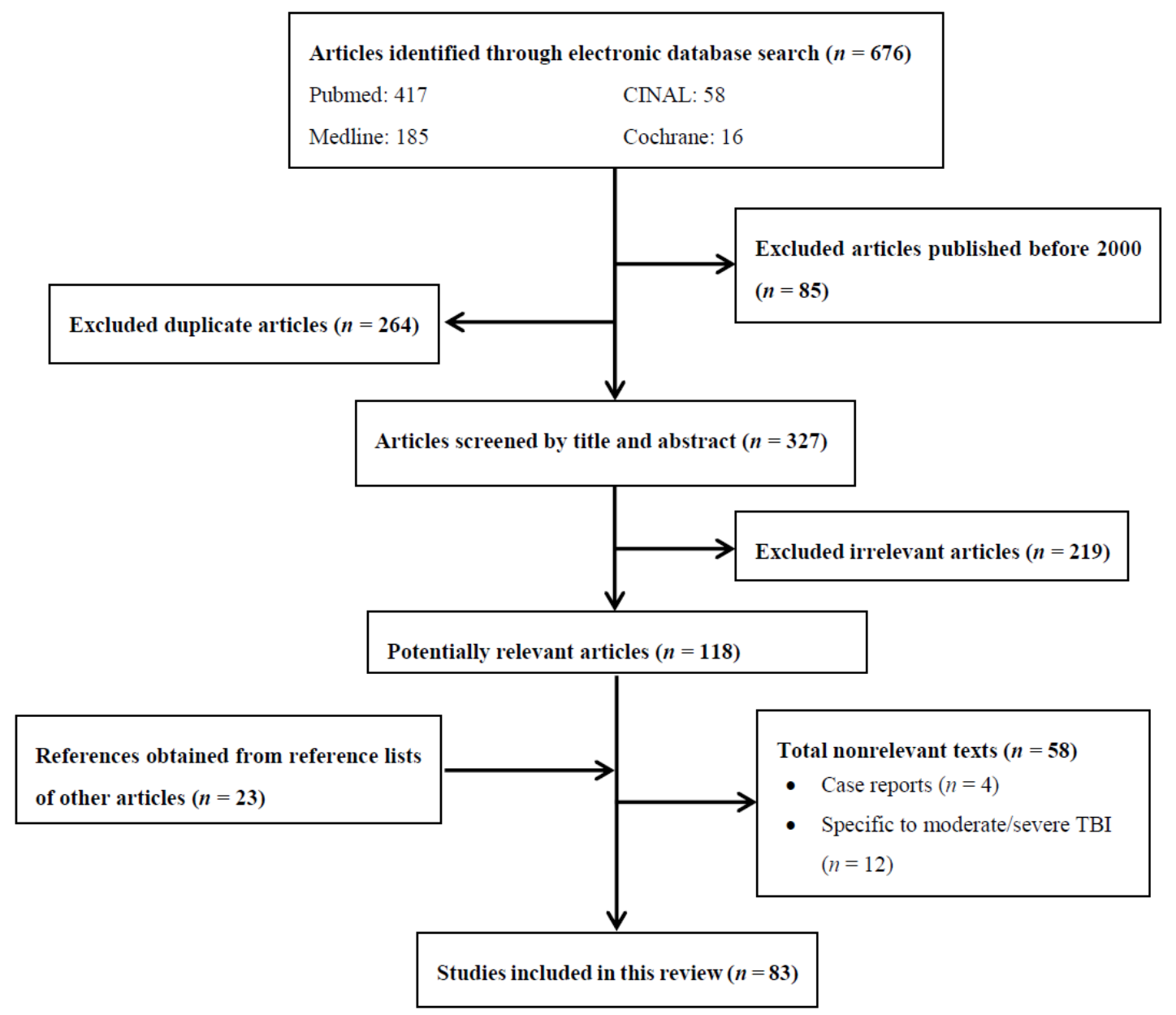

Figure 1. Process flow chart.

\section{Introduction}

Traumatic brain injury (TBI) is a leading cause of disability in the United States. The Center for Disease Control and Prevention recently reported that in 2013 there were 2.8 million cases of TBI-related ER visits, hospitalizations, and deaths [1]. Of the annual cases of traumatic brain injury, the World Health Organization estimates that $70 \%$ to $90 \%$ of those are mild TBI [2]. The most common groups to sustain a mild TBI are males, teenagers, and young adults, while the most common causes are falls, motor-vehicle collisions, and assault [2]. Despite the high incidence, mTBI numbers are likely an underestimation [1]. One study found that in the emergency department, $56 \%$ of cases that qualified as mTBI did not carry a documented diagnosis, suggesting that many patients are potentially undiagnosed [3]. One proposed reason mTBI is frequently missed is that standard imaging in patients with mTBI does not show hemorrhage or other obvious structural abnormalities [4]. Likewise, mTBI-associated sleep disturbances are often unnoticed in the ED and primary care clinics as providers tend to focus on vision changes, nausea, vomiting, head and neck pain [5]. This suggests a need for a higher index of suspicion, targeted questioning and appropriate screening tools to improve diagnosis of both mTBI and associated sleep disturbance [6].

According to the American Congress of Rehabilitation Medicine (ACRM), mild traumatic brain injury is defined as traumatically induced physiologic disruption of brain function that manifests with at least one of the following: any period of loss of consciousness (LOC), memory loss before or after injury, alteration in mental state at time of injury (i.e., feeling dazed, disoriented, confused) or focal neurological deficit(s) that may or may not be transient [7]. Classification as mild requires that severity does not exceed a Glasgow Coma Scale (GCS) score between 13 and 15 after 30 min, 
a PTA of greater than $24 \mathrm{~h}$, or LOC of more than $30 \mathrm{~min}$ [5]. Common symptoms associated with mTBI include headache, dizziness, bad taste, sleep disturbance, nausea/vomiting, impaired balance and coordination, tinnitus, and vision changes [8]. TBI also results in significant cognitive, emotional, and behavioral disorders which all increase morbidity [9]. Poor sleep may develop acutely and last several years post-injury and is described by those who experience a mild TBI as one of the most debilitating consequences [10].

\section{Pathophysiology of Sleep Disturbance after TBI}

Traumatic brain injury is classified into primary and secondary brain injury. Primary injury refers to the structural damage created upon impact. Secondary injury refers to the damage from subsequent cellular processes following primary injury such as excitotoxicity, free radical generation, calcium-mediated damage, hypoxia, and increased intracranial pressure [11,12]. Unsurprisingly, these mechanisms can incur structural, biochemical, and genetic changes implicated in sleep disturbance.

Coup-countrecoup injury typically occurs at the base of the skull in areas of bony prominences so the anterior temporal and inferior frontal regions, including the basal forebrain, are frequently injured. Since the basal forebrain contributes to sleep initiation, injury to this region can lead to insomnia symptoms [8]. The structure of the tentorium has also been associated with sleep pathology. When controlling for cognitive function and MTBI severity, researchers found those with sleep-wake disturbances had longer tentorial lengths and flatter angles, suggesting closer proximity of the tentorial edge to the pineal gland. The authors reason this proximity increases the risk of direct impact between the tentorium and pineal gland subsequently disrupting melatonin pathways [13]. Another study with mTBI patients measured fractional anisotropy (FA) with MRI as a representation of white matter integrity. In patients with sleep disturbance there was reduced parahippocampal FA, which was strikingly similar to findings of early Alzheimer dementia, in which sleep-wake disturbance is one of the earliest symptoms [14]. Using rodent models of TBI, researchers found increased reactive microglia in the thalamus preceding development of sleep disruption. The authors postulate that the inflammatory response may interfere with the thalamocortical network, which regulates sleep-wake patterns [15].

Sleep disturbance after TBI is associated with numerous biochemical changes as well. One study demonstrated lower evening melatonin production in TBI patients compared to healthy controls, which was associated with decreased sleep efficiency, increased wake after sleep onset (WASO), and higher rates of depression and anxiety [16]. Decreased melatonin likely arises from the aforementioned pathway disruptions and/or damage to the suprachiasmatic nucleus [8]. Other reported biochemical associations include changes in levels of hypocretin-1, dopamine, and serotonin, which are neurotransmitters involved in sleep modulation [17]. Decreased levels of IGF-I and testosterone were also found specifically after blast-induced mTBI [18]. More on the distinction of mTBI from blast injury is discussed in Section 5.1.

A variety of genes involved in inflammation, glial function, neuronal plasticity, immunity, and circadian rhythm have implications on sleep disturbance post-TBI [19]. For example, in rodent models several plasticity genes like Bdnf, Homer $1 a$, and Fos have decreased expression a few days after mTBI. This is important because these plasticity genes have demonstrated roles in maintaining sleep homeostasis [19]. Also, in rodent models the astrocyte marker Gfap was elevated in the cortex after TBI and prior to the development of sleep disruptions, suggesting that astrocyte activation may contribute to sleep modification $[15,19]$. In mTBI patients, one of the clock genes, PERIOD3 (PER3), was found to be associated with changes in sleep recovery. Specifically, the PER3 gene carries a polymorphism that comes in either 4 or 5 tandem repeats and patients who were carriers of 5 repeats interestingly reported improved sleep quality but shorter sleep duration compared to noncarriers at 6 weeks post-mTBI [20]. 


\section{Sleep Architecture Changes Seen after mTBI}

Sleep architecture refers to the organization and cyclical pattern of normal sleep with specific corresponding electroencephalographic (EEG) activities [21]. Sleep is comprised of slow-wave sleep and paradoxical sleep. Within slow-wave sleep there are 4 stages. Stages 1 and 2 are considered light sleep, while stages 3 and 4 are considered deep sleep. These stages can fall under the term "non-rapid eye movement (NREM) sleep". The paradoxical sleep stage involves rapid eye movement (REM) sleep which has similar EEG activity to wakefulness and is the stage in which dreaming occurs [21]. In adults, NREM takes up about $20 \%$ of the night, while REM takes up about $80 \%$ and each stage of sleep is thought to perform independent yet complementary restorative functions [4].

When it comes to sleep architecture after mild TBI, patients generally experience "sleep fragmentation" referring to reduced total sleep time and a greater proportion of sleep in light sleep stages [20]. Observed changes of sleep in mTBI patients include increased stages 1 and 2 sleep and decreased REM sleep $[17,22,23]$. One study also found no significant difference in sleep and REM latencies in mTBI patients compared to controls [22].

Even though absence of objective findings is common in mTBI patients reporting sleep disturbance, studies recommend that the subjective experience should take precedence $[17,22,24]$. While mTBI patients with insomnia also tend to underestimate the time spent asleep, subjective sleep is still predictive of depression, anxiety, and general distress [25,26]. As insomnia is by definition a subjective complaint, it is important not to disregard patients even in the absence of objective evidence.

\section{Insomnia and mTBI}

Insomnia is characterized by poor sleep quantity or quality in the forms of delayed sleep onset, nocturnal awakenings with difficulty returning to sleep, waking too early, and not feeling rested despite adequate sleep hours. A required criterion for diagnosing insomnia of any form is that it leads to distress and subjective impairment in the daytime [27]. Insomnia is important to address as it affects patients both psychologically and cognitively throughout recovery and impedes a patient's return to normal functioning.

Sleep disorders such as insomnia, sleep apnea, narcolepsy, periodic limb movement disorder are all more prevalent in TBI patients compared to the general population [28]. Insomnia is the most commonly reported sleep disturbance with approximately $40 \%-65 \%$ of mTBI patients reporting symptoms of insomnia [12]. However, there are conflicting findings on whether insomnia among TBI patients are over- or underreported. In a survey of 452 patients with TBI, the majority of which were severe TBI (59.9\%), 50.2\% reported insomnia symptoms, while only $29.4 \%$ fulfilled the DSM-IV diagnosis of insomnia [29]. Another study of mTBI patients by Sullivan et al. found that although $42 \%$ of their sample had insomnia, only $16 \%$ self-reported an insomnia diagnosis [30]. The contrary findings may suggest an association between severity of brain injury and insomnia symptoms, a relationship that will be further discussed in Section 5.2.

A popular model of insomnia contains two components, a general predisposition to developing insomnia followed by an acute stressor [17]. There are various interpretations on how this model applies to TBI. In one interpretation, those suffering from insomnia post-TBI may have had previous episodes of insomnia or a family history. The acute stressor would therefore be the TBI itself [17]. Another interpretation surmises that both aspects of the model may be affected by TBI because pathophysiological changes of the brain create a predisposition for insomnia while acute stressors come in the forms of comorbidities such as pain, depression, and anxiety $[11,18]$. TBI patients will also often experience multiple psychosocial stressors simultaneously such as inability to return to work, financial difficulties, redefined familial roles, and strained social relationships. Increased familial discord, marital problems, and litigation procedures have been documented with TBI patients and are obvious sources of significant stress [31]. The patient experience and environment are therefore important to consider in management of these patients. 


\section{Epidemiology of Insomnia after mTBI}

Within the general population, sufferers of insomnia are more likely to be white, older, female, and unmarried. Although prevalence of insomnia symptoms increases with age in the general population, sleep dissatisfaction and diagnoses were found to be independent of age [32]. The demographic characteristics differ in the context of TBI as a study by Fichtenberg et al. of patients with various severities of TBI found no relationship between insomnia and gender, age, or education [33]. In the mTBI population, age at time of injury may have implications on the development of insomnia. For example, adolescence is a time of increased risk for sleep problems due to physiologic changes and increased societal and academic demands. Thus, when adolescents experience a mild TBI they have a higher predispositon than younger children to develop chronic sleep problems [34]. It is generally believed that TBI outcomes like sleep disturbance worsen with increased age possibly due to reasons such as decreased ability to compensate, decreased cerebral reserve, and pre-existing comorbidities [35]. When it comes to mTBI, literature remains divided on how age affects outcomes [35]. Some studies suggest increased symptom severity with age; however, a study by Hu et al. found that middle-aged mTBI patients (36-55 years) had a higher severity of sleep disturbance compared to elderly patients [35]. The authors suggest that this finding may be due to middle-aged patients noticing more significant deviations from their baseline functional status and experiencing more daily stressors such as employment and living with dependents. Although studies are revealing potential risk factors, further research is needed to better comprehend the risk factors that predispose and precipitate insomnia after mild TBI.

\subsection{Repeat TBI and Blast Injury}

Repeat mTBIs are found to increase the likelihood and severity of insomnia as well as cause persistent deficits in spatial learning and memory, subacute anxiety, and depression relative to the aftermath of a single mTBI [36]. A study of military personnel found that $20 \%$ of patients with a single mTBI reported insomnia, whereas $50 \%$ of patients who experienced multiple mTBIs reported insomnia [37]. It is worth noting that blast injury accounts for around $60 \%$ of military-related TBIs of which $80 \%$ are classified as mild TBI [38]. Unlike blunt trauma associated with other forms of TBI, blast injury produces shockwaves that create propagating pressure transients that can lead to diffuse axonal injury, contusion, edema, and hemorrhage [39]. This describes only primary blast injury and it is also important to consider potential damage from shrapnel, thermal effects of detonation, and psychological consequences [39]. In a broad context, TBI and blast-related TBI (bTBI) are often discussed in the same vein because evidence points to similar impairments after injury. One study comparing bTBI to other causes of brain injury found no significant differences in sleep impairment along with cognitive impairment, pain, and other symptoms post-injury [40]. However, distinct consequences of bTBI include hearing loss, tinnitus, and increased incidence of post-traumatic stress disorder (PTSD) symptoms [39]. Therefore, consequences of blast-related TBI compared to those from other forms of TBI are not synonymous and differences are important to keep in mind in practice and literature. Regarding repeat TBIs, sleep disturbance is itself a risk factor for repeat brain injury. Insomnia is known to increase the risk of industrial and vehicle accidents, thereby increasing risk of TBI and reoccurrence [27]. One survey found that chronic insomnia doubled the risk of automobile accidents due to sleepiness [41]. Since insomnia after TBI increases risk for reoccurrence, safety precautions and follow-up should be emphasized.

\subsection{Implications of TBI Severity}

A frequently mentioned and somewhat counterintuitive finding is that mild TBI is more strongly associated with insomnia and other sleep disturbances compared to more severe TBI [35]. Opposition to this correlation includes a prospective study by Baumann et al., which found that severity of inciting head injury did not predict sleep-wake disturbances [42]. Despite this finding, evidence generally 
supports the relationship between insomnia and milder TBI $[29,33,43]$. The higher prevalence of insomnia in mTBI patients may be secondary to increased awareness of impairment and disability leading to an increase in self-reporting [33]. Mild TBI patients may also be under more pressure to reintegrate into normal life which could lead to increased stress and sleep issues $[8,35]$.

\section{Prognosis}

Prognosis of mTBI is typically good with one study finding that almost all previously healthy adults (96\%) return to work/normal activities within one year post-mTBI [44]. Despite this prognosis, a large prospective cohort study discovered a that significant minority of patients after mild TBI, around $20 \%$, are not functionally recovered even by one year post-injury [45]. Sleep difficulty is one of the postconcussive symptoms that is assumed to resolve spontaneously over time. Along with depression and anxiety, all are expected to improve; however, one study found that only sleep quality improved to the pre-mTBI level by 6 weeks [46]. This implies that recovery from sleep disturbance is relatively rapid, yet studies that extend beyond the subacute stage suggest otherwise. For example, a study found that for veterans with mTBI, poor sleep quality lasted on average 6 years post-injury and was independent of combat exposure, PTSD, mood disorders, anxiety, and substance use [47].

It is generally accepted that negative outcomes of mTBI resolve even more rapidly within the younger population with complete recovery expected within 2-3 months for children and adolescents [34]. However, a longitudinal study of children between the ages of 8-16 years found little improvement in sleep difficulties after 6 months and $28 \%$ still experienced poor sleep at one year post-mTBI [48]. In the study, sleep quality at 1 month was predictive of symptom severity and behavioral outcomes at 12 months, suggesting that prompt intervention may facilitate recovery [48]. Persistent sleep impairment among the younger population is reinforced with another study that found that around a third of adolescents after mTBI had greater levels of sleep disturbance compared to healthy peers even 6 years after injury [49]. These findings appear to counter the common belief of mTBI's speedy recovery especially in younger patients. While other symptoms post-mTBI may resolve, these study findings (further detailed in Table 1) suggest that sleep disturbance persists for years in a significant proportion of patients regardless of age group. 
Table 1. Summary of study findings of sleep disturbance chronicity after mild traumatic brain injury (mTBI).

\begin{tabular}{|c|c|c|c|c|c|}
\hline Study & Study Design & Participants & Sleep Outcome Measure & Results & Limitations \\
\hline & & mTBI group: & & & \\
\hline & & $\begin{array}{l}n=100 \\
\text { Age: }>20 \text { years, } \\
\text { (mean }=38.88 \text { years) }\end{array}$ & & \multirow{2}{*}{$\begin{array}{l}\text { Baseline mTBI PSQI scores } \\
\text { significantly different from } \\
\text { scores of control } \\
\text { At } 6 \text { weeks follow-up, mTBI } \\
\text { PSQI scores improved } \\
\text { significantly and were not } \\
\text { significantly different from } \\
\text { scores of control }\end{array}$} & \multirow{2}{*}{$\begin{array}{l}\text { Medication use may have } \\
\text { interfered with assessment } \\
\text { Unidentified } \\
\text { pre-existing comorbidities } \\
\text { Only evaluated subacute stage } \\
\text { of sleep quality } \\
\text { Self-report }\end{array}$} \\
\hline Ma et al. (2014) [46] & Prospective cohort & $\begin{array}{l}\text { Control group: } \\
\quad n=137, \\
\quad \text { Age: }>20 \text { years } \\
\text { (mean: 29.86 years) } \\
\quad \text { without TBI }\end{array}$ & $\begin{array}{l}\text { Pittsburgh Sleep Quality } \\
\text { Index (PSQI) }\end{array}$ & & \\
\hline McMahon et al. (2014) [45] & Prospective cohort & $\begin{array}{l}\text { mTBI study population: } \\
\quad n=375 \\
\quad \text { Age: }>18 \text { years, } \\
\text { (mean }=44 \text { years) }\end{array}$ & $\begin{array}{l}\text { Postconcussion Syndrome } \\
\text { (PCS) Symptom Checklist }\end{array}$ & $\begin{array}{l}\text { At } 3 \text { months, } 50.2 \% \text { of mTBI } \\
\text { patients report at least one } \\
\text { sleep symptom }(n=348) \\
\text { At } 1 \text { year follow-up, } 53.5 \% \text { of } \\
\text { mTBI patients report at least } \\
\text { one sleep symptom }(n=199)\end{array}$ & $\begin{array}{l}\text { No control group } \\
\text { Loss of patients to follow-up } \\
\text { Did not analyze contribution o } \\
\text { medical history on outcome } \\
\text { Self-report }\end{array}$ \\
\hline Martindale et al. (2017) [47] & Cross-sectional & $\begin{array}{l}\text { mTBI study population: } \\
\quad \text { Veterans }(n=527) \\
\text { Age: }>21 \text { years, } \\
\text { (mean }=35.47 \text { years })\end{array}$ & $\begin{array}{l}\text { Pittsburgh Sleep Quality } \\
\text { Index (PSQI) }\end{array}$ & $\begin{array}{l}56.2 \% \text { of sample reported } \\
\text { clinically significant poor } \\
\text { sleep quality } \\
\text { Poor sleep quality lasts on } \\
\text { average } 6 \text { years independent of } \\
\text { combat exposure, } \\
\text { post-traumatic stress disorder } \\
\text { (PTSD), mood disorders, } \\
\text { anxiety disorders, } \\
\text { and substance use disorders }\end{array}$ & $\begin{array}{l}\text { Deployment related-mTBI } \\
\text { limits generalizability } \\
\text { Cross-sectional data, unable to } \\
\text { evaluate temporal relationship } \\
\text { Self-report }\end{array}$ \\
\hline $\begin{array}{l}\text { Theadom and Parag et al. } \\
\text { (2016) [50] }\end{array}$ & $\begin{array}{c}\text { Longitudinal } \\
\text { population study }\end{array}$ & $\begin{array}{l}\text { mTBI study population: } \\
\quad n=341 \\
\quad \text { Age: }>16 \text { years, } \\
\quad \text { (mean }=37.5 \text { years) }\end{array}$ & $\begin{array}{l}\text { Rivermead Post } \\
\text { Concussion Symptoms } \\
\text { Questionnaire (RPQ) }\end{array}$ & $\begin{array}{l}43 \% \text { of sample reported sleep } \\
\text { disturbance at baseline } \\
\text { At } 12 \text { months } 32 \% \text { still reported } \\
\text { sleep disturbance }\end{array}$ & $\begin{array}{l}\text { Lack of information on prior } \\
\text { mood, psychiatric and } \\
\text { medical conditions } \\
\text { Self-report }\end{array}$ \\
\hline
\end{tabular}


Table 1. Cont

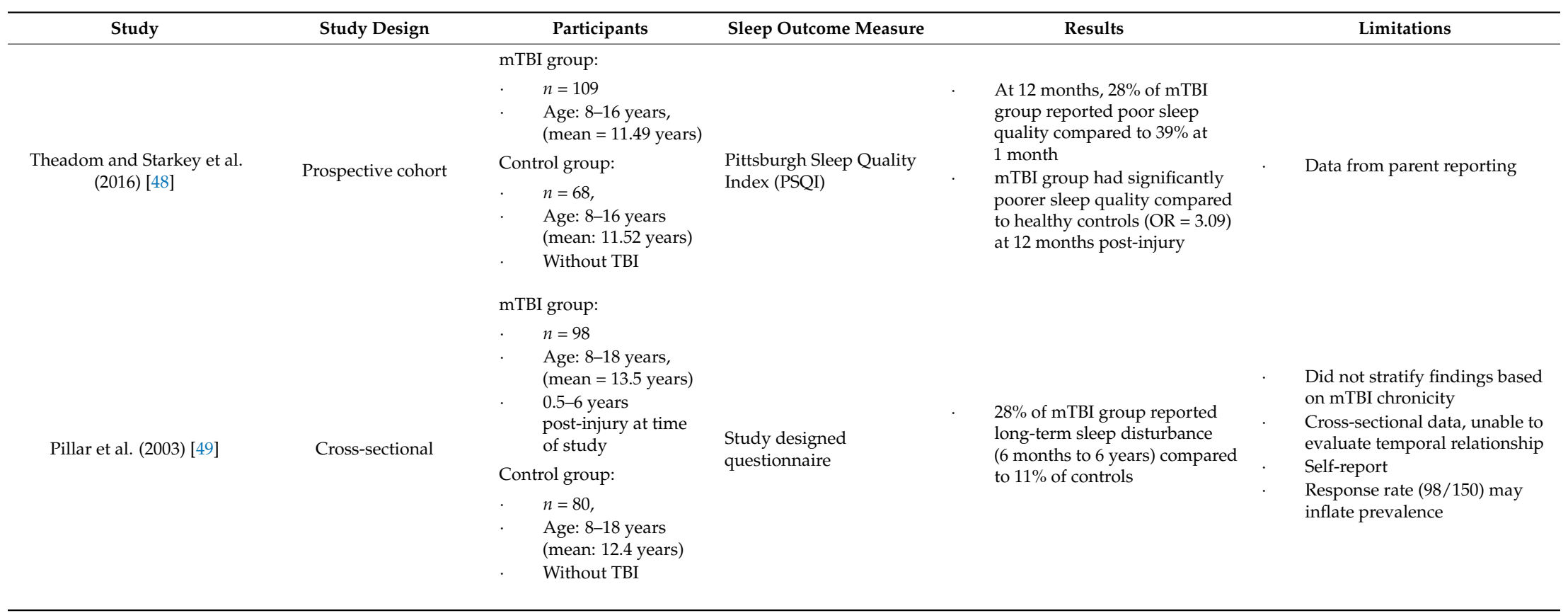




\section{Consequences of Sleep Impairment}

Sleep quality impacts all areas of daily functioning and is also crucial for the recovery process. Memory, attention, and executive functions are the cognitive domains most affected by sleep impairment [51]. This aligns with recent evidence demonstrating the importance of sleep on neural growth and plasticity, learning, and memory consolidation [4]. Poor sleep was found to be significantly predictive of poorer post-concussion symptoms, mood, community integration, and cognitive ability at one year post-injury [52]. Sleep disruption may also act as a cellular stressor and lead to cognitive decline. Studies found that disrupted sleep leads to accumulation of hyperphosphorylated tau and amyloid beta plaque accumulation from oxidative stress [23].

Fatigue is a common sequelae post-mTBI that emerges as soon as a few days post-injury [53]. There exist two supported models of cognitive fatigue after mTBI, including fatigue secondary to increased work to process information and fatigue secondary to impaired sleep [54]. One study found the prevalence of fatigue to be $68 \%$ at one week post-mTBI and decrease to $38 \%$ after 3 months [55]. Although fatigue is found to be higher at the 4 month mark in mTBI compared to sTBI, fatigue tends to reduce over time after mild TBI and increase after severe [53]. However, even by 6 months after sustaining an mTBI, $32 \%-34 \%$ of individuals reported fatigue $[55,56]$. The concern regarding the high prevalence of fatigue in the mTBI population is association with higher reported levels of functional impairment, depression, and cognitive difficulties [53,56].

For adolescents, studies find that persistent sleep impairment following mTBI is associated with poorer quality of life, greater depressive symptoms and decreased participation in normal roles [34]. In a study of university students (18-25 years) with mTBI, sleep impairment led to increased daytime dysfunction along with lower levels of enthusiasm and energy in completing tasks. Participants also experienced behavioral problems which were moderately correlated with sleep-related daytime dysfunction in the forms of social withdrawal, poor relationships, clumsiness, and speech difficulties [57]. The consequences of poor sleep in these populations are particularly detrimental during a time when social integration, academic functioning, and development are critical.

Within the working population, individuals with sleep impairment present with greater absenteeism, increased presenteeism, lower job satisfaction and work productivity loss [27,41]. In a study of workers with delayed recovery from mTBI, insomnia was the only variable associated with greater odds of disability while age, sex, education, income, and marital status were not associated with greater perceived disability [58]. Therefore, prioritizing sleep management in these patients may expedite return to normal functioning and mitigate potential sources of stress.

\section{Differential Diagnosis of Sleep Disturbance after TBI}

\subsection{Pain}

Pain is one of the most frequent complaints post-mTBI and along with insufficient management is a significant contributor to sleep disturbance [59]. Comorbid pain was found in over $60 \%$ of mTBI patients and often presented in the forms of headaches, joint, neck, shoulder and back pain [59-61]. Similar to the trends of sleep disturbance, reports of pain are more frequent in the mTBI population than in more severe injuries. A possible explanation is that patients with severe injuries are often bedridden and treated with paralytic agents allowing healing of cervical injuries. Those with mild injuries may continue to use those damaged muscles and ligaments, thereby interfering with healing [62]. Those with severe injuries may also have more difficulty communicating their pain to providers [62]. In early recovery, Suzuki et al. observed that pain increased sleep need to over $8 \mathrm{~h}$ in a third of mTBI patients [60]. In mTBI patients with pain, fast beta and gamma electroencephalographic activity were observed in frontal, central, and occipital electroencephalographic (EEG) within all sleep stages. This finding suggests that the increased need for sleep is secondary to persistent wake EEG activity, leading to unrestful sleep [59]. Evaluation of pain is a necessary precursor to the management of new sleep complaints after mTBI as adequate pain management may treat insomnia as well. 


\subsection{Sleep Apnea}

Behind insomnia, sleep apnea is one of the most frequently diagnosed sleep disorders post-TBI [28]. Both obstructive and central sleep apneas are more prevalent in the TBI population and seem to arise from a complex interaction between brain injury, decreased arousal, and impaired respiratory effort $[6,63]$. Obstructive sleep apnea (OSA) refers to intermittent episodes of upper airway obstruction that reduces blood oxygenation [28]. Studies have demonstrated prevalence of obstructive sleep apnea to be $25 \%$ to $35 \%$ following TBI of any severity which is substantially higher than general population findings [63].

While many patients complain of insomnia and will lack objective findings, patients with diagnosable sleep apnea will often fail to recognize the problem and only describe poor day time vigilance [28]. Although costly and time-consuming, the gold standard for diagnosing sleep apnea is polysomnography (PSG), which will commonly find increased sleep onset latency, poor sleep efficiency, and decreased REM latency [6]. Sleep apnea is predictive of higher all-cause mortality and recurrent vascular events after stroke and TIA implying urgency in diagnosing and treating sleep-disordered breathing within the TBI population [6]. It is worth noting that studies that found sleep apnea of any severity significantly increases risk of TBI [64]. Therefore, sleep apnea may also be an important target in the prevention of TBI. Treatment is unchanged to those with other causes of sleep-disordered breathing where positive airway pressure (PAP) is the standard of care [4].

\subsection{Post-Traumatic Stress Disorder}

The majority of studies on the relationship between post-traumatic stress disorder (PTSD) and traumatic brain injury understandably involve veterans where the rate of PTSD after TBI ranges from around $27 \%$ to $44 \%$ [65]. Among the civilian population suffering from nonmilitary trauma, one study found that $14 \%$ to $56 \%$ of TBI patients had comorbid PTSD [65]. PTSD is diagnosed via criteria released by the American Psychiatric Association which shares many symptoms with TBI, often causing attribution of symptoms to be difficult [66]. One of the shared and core symptoms of PTSD is sleep disturbance, found in around 70\% of PTSD patients [12]. Although it is difficult in PTSD-TBI comorbid patients to assess the roles each play in sleep impairment, certain sleep pathology may be distinguishable between the two. One study comparing TBI and PTSD patients among returning veterans found no differences in the rates of OSA, excessive awakenings and daytime sleepiness but on PSG, PTSD patients demonstrated greater arousal frequency while TBI patients demonstrated greater slow-wave sleep [67].

Similar to symptoms, the treatment of sleep disturbance in PTSD and TBI patients overlaps. Despite similarities, certain treatments may be prioritized depending on the presence of comorbid PTSD with TBI. VA/DOD Clinical Practice Guidelines for the treatment of PTSD recommend prazosin, an alpha-1 adrenergic antagonist, as treatment for sleep impairment and nightmares in PTSD [65,66]. Other supported pharmacologic options for PTSD include venlafaxine, a serotonin norepinephrine reuptake inhibitor (SNRI), and selective serotonin inhibitors such as sertraline and paroxetine [65]. Likewise, cognitive behavioral therapy (CBT) is a mainstay of treatment for sleep impairment in TBI but studies recommend trauma-focused CBT for comorbid PTSD in reducing symptoms [65]. For these patients, there is likely a complex interplay between TBI and PTSD that results in sleep impairment and currently cannot be separated into exclusive contributions. Therefore, more research is needed in studying the associations between sleep disturbance and TBI patients with comorbid PTSD. Recommended management of sleep disturbance in the PTSD population differs slightly from TBI and is therefore up to clinical judgment for attempting PTSD targeted treatments.

\subsection{Circadian Rhythm}

Circadian rhythm disorders are sometimes mistaken for insomnia post-TBI. Circadian rhythm disorder refers to disruption of the normal $24 \mathrm{hr}$ cycle of body patterns such as body temperature 
and melatonin secretion [10,23]. Circadian sleep disturbances come in the forms of irregular sleep-wake pattern and more commonly delayed sleep phase syndrome [68]. A study by Ayalon et al., using actigraphy, salivary melatonin, temperature measurement, and polysomnography, found that $36 \%$ of patients who were diagnosed with insomnia actually had circadian sleep disturbance [68]. The distinction between insomnia and circadian rhythm disorder is important as treatment differs. Rather than prescribe hypnotics, melatonin or bright light therapy are more appropriate for these patients [68].

\section{Treatment}

Many treatment options are available for patients suffering from insomnia post-TBI (Table 2). Despite this, insomnia is often undertreated and patients seek treatment independent of health care providers in the forms of over-the-counter (OTC) medications and alcohol [69]. In the context of TBI, one study found that around $60 \%$ of those fulfilling diagnosis of insomnia were left untreated [29].

Similar to the management of most chronic medical conditions, providers should begin with conservative measures and proceed to more aggressive options only when necessary. As was discussed, this begins with ruling out common comorbidities as causes of sleep impairment. After other etiologies are considered, further interventions can be sought.

\subsection{Sleep Hygiene}

Sleep hygiene is a broad term that refers to adjustments that improve sleep health. The basis is to replace stimulating behaviors with sleep-promoting behaviors. Examples of adjustments include exercising, consuming a snack before bed, keeping the bedroom dark, limiting noise, maintaining a regular sleep schedule, and reducing intake of stimulants and alcohol [70]. Individuals with chronic insomnia will often spend more time in bed and nap during the day leading to irregular sleep-wake schedules. These behaviors likely desynchronize the natural cycle and contribute to sleep disturbances [31]. Many studies advocate sleep hygiene incorporation into the care plans of TBI patients as it is low cost, low risk, and noninvasive [71]. Studies have demonstrated that increased knowledge of sleep hygiene post-TBI was associated with better sleep habits and subsequent sleep quality improvements [72].

\subsection{Cognitive Behavioral Therapy \& Digital CBT}

Cognitive behavioral therapy (CBT) encompasses sleep hygiene along with other techniques such as relaxation, sleep restriction, and stimulus control. The goal of CBT is to reduce unrealistic expectations and anxiety towards sleep by identifying and mitigating deleterious thoughts surrounding and during sleep [70]. A key component of CBT is the sleep diary that includes self-reported data on time in bed, medication use, caffeine intake, exercise, and awakenings as an attempt to eliminate recall bias [70]. A systematic review by Bogdanov et al. demonstrated significant improvements in insomnia severity and sleep diary data after CBT among patients with TBI and comorbid insomnia. The benefits of CBT were found to appear within 1-2 weeks of implementation and sustained by time of follow-up 3 months later [73]. Another study found that patients undergoing CBT also had significant improvements in both fatigue and depression that persisted at follow-up 2 months later [74]. These findings support why CBT is widely advocated as a standard of care for insomnia including within the TBI population. 
Table 2. Pros/Cons of Commonly Used Treatments for Insomnia after TBI.

\begin{tabular}{|c|c|c|}
\hline Intervention & Pros & Cons \\
\hline \multicolumn{3}{|l|}{ Sleep Hygiene Counseling } \\
\hline & $\begin{array}{l}\text { Effective in improving sleep quality and reducing } \\
\text { daytime sleepiness }\end{array}$ & $\begin{array}{l}\text { Variable recommendations, provider-dependent } \\
\text { Issue of non-compliance }\end{array}$ \\
\hline & Inexpensive, low risk, noninvasive & Patients may be non-receptive to \\
\hline & Persistent improvement on sleep & indirect intervention \\
\hline & $\begin{array}{l}\text { Recommendations may be catered to } \\
\text { patient environment }\end{array}$ & $\begin{array}{l}\text { Barriers may exist for implementing changes } \\
\text { (ex. living arrangement, occupation, economic } \\
\text { status, disability, dependents, etc.) }\end{array}$ \\
\hline \multicolumn{3}{|l|}{ Cognitive Behavioral Therapy (CBT) } \\
\hline & $\begin{array}{l}\text { Effective in improving insomnia severity, sleep } \\
\text { efficiency, and quality }\end{array}$ & $\begin{array}{l}\text { Time commitment (meetings, maintaining } \\
\text { sleep diary) }\end{array}$ \\
\hline & Includes sleep hygiene counseling & Issue of noncompliance \\
\hline & Low risk, noninvasive & Financial costs \\
\hline & . $\quad$ Benefits appear within 1-2 weeks & Provider dependent efficacy \\
\hline & Persistent improvement on sleep & Variable settings (one to one or in group settings) \\
\hline & $\begin{array}{l}\text { Newer digital CBT may address accessibility } \\
\text { and scalability }\end{array}$ & \\
\hline \multirow[t]{5}{*}{$\begin{array}{l}\text { Benzodiazepines } \\
\text { (i.e., flurazepam, lorazepam, estazolam) }\end{array}$} & & \\
\hline & Effective in increasing total sleep time and & Risk of dependency and abuse \\
\hline & improving sleep quality & $\begin{array}{l}\text { Associated with daytime sedation and } \\
\text { cognitive impairment }\end{array}$ \\
\hline & & Increases risk of falls/accidents \\
\hline & & Short-term benefit \\
\hline
\end{tabular}


Table 2. Cont.

\begin{tabular}{|c|c|c|}
\hline Intervention & Pros & Cons \\
\hline $\begin{array}{l}\text { Z-drugs } \\
\text { (i.e., zaleplon, zolpidem, zopiclone) }\end{array}$ & $\begin{array}{l}\text { Effective in increasing total sleep time and } \\
\text { improving sleep quality } \\
\text { Well tolerated, no daytime cognitive or } \\
\text { psychomotor impairment } \\
\text { Significantly lower incidence of dependence } \\
\text { compared to benzodiazepines }\end{array}$ & $\begin{array}{l}\text { Associated with daytime sedation } \\
\text { Potential psychological dependency and } \\
\text { abuse potential } \\
\text { May cause sensory distortions } \\
\text {. } \quad \text { Short term benefit } \\
\text { Lack of research in TBI patients }\end{array}$ \\
\hline Trazodone & $\begin{array}{l}\text { Increases sleep duration in insomnia and with } \\
\text { comorbid depression } \\
\text { Generally well tolerated } \\
\text { Comparable antidepressant effect to selective } \\
\text { serotonin reuptake inhibitors (SSRI) and tricyclic } \\
\text { antidepressants(TCA) } \\
\text { Decreased anticholinergic effects compared } \\
\text { to TCA }\end{array}$ & $\begin{array}{l}\text { Associated with daytime sedation, headache, } \\
\text { dry mouth, sexual dysfunction, } \\
\text { orthostatic hypotension } \\
\text { Short-term benefit } \\
\text {. Lack of research in TBI patients }\end{array}$ \\
\hline $\begin{array}{l}\text { Melatonin \& Melatonin Agonists } \\
\text { (i.e., ramelteon, tasimelteon) }\end{array}$ & $\begin{array}{l}\text { Increases total sleep time and decreases } \\
\text { sleep latency } \\
\text { OTC melatonin affordable and accessible } \\
\text { No risk of dependency or tolerance }\end{array}$ & $\begin{array}{ll}\text { Agonists are costly } \\
\text {. } & \text { Short-term benefit }\end{array}$ \\
\hline
\end{tabular}


"Digital CBT" has received growing interest in recent years and is a general term referring to CBT provided via web and mobile platforms [75]. A recent RCT comparing dCBT to sleep hygiene counseling for general insomnia found small improvements in functional health and psychological well-being, but large improvements in sleep-related quality of life and insomnia symptoms [76]. When comparing dCBT to CBT, meta-analyses demonstrate that the effects of dCBT on insomnia at increasing total sleep time, decreasing sleep onset latency and decreasing WASO are in the ranges of conventional CBT, suggesting similar effectiveness [75] Relative to CBT, dCBT also tended to be more cost-effective with lower societal and healthcare costs [75]. Besides similar efficacy and improved cost-effectiveness, dCBT's ability to disseminate effective treatment for insomnia is likely its greatest advantage [75]. Although dCBT appears to be a promising avenue for treatment, much research is needed on the effects of dCBT for insomnia post-TBI.

\section{Pharmacologic Options}

\subsection{Benzodiazepines/Z-Drugs}

Benzodiazepines such as diazepam, lorazepam, and alprazolam have largely fallen out of use due to side effects such as dependency, daytime sedation, cognitive impairment, and increased risk of falls/accidents that are deleterious to recovery from TBI [77]. The Z-drugs (zapleplon, zopliclone, and zolpidem) are alternatives. Similar to benzodiazepines, Z-drugs are also GABA agonists but act more specifically on the type 1 receptor [78]. Z-drugs are not without their potential side effects, including daytime sedation and sensory distortions, but generally have no daytime consequences on cognitive and psychomotor function. Z-drugs also have shorter half-lives compared to benzodiazepines ranging from $1 \mathrm{hr}$ with zapleplon to $5 \mathrm{hrs}$ with zopliclone. It is believed that the selective target and faster offset of action contribute to the preferable side effect profile of Z-drugs as compared to benzodiazepines [78]. While Z-drugs have a significantly lower incidence of dependence relative to benzodiazepines, there is still a risk of abuse especially in patients with a history of substance abuse, dependence, or psychiatric diseases [79]. Research on the efficacy of Z-drugs within the TBI population is limited. One study comparing the efficacies of lorazepam and zopiclone in treating insomnia for stroke and brain injury patients found that both groups slept more than $7 \mathrm{~h}$ and did not differ in quality of sleep, suggesting similar effectiveness [80]. Long-term therapeutic benefits of both benzodiazepines and Z-drugs are limited, so while indicated for short-term use, one should defer to attempting non-pharmacologic treatments.

\subsection{Trazodone}

Trazodone is a heterocyclic antidepressant and one of the most frequently prescribed drugs for treatment of insomnia in TBI patients [78]. Its mechanism in humans remains poorly understood; however, animal models have shown that trazodone inhibits serotonin re-uptake [78]. For TBI patients, trazodone is generally well tolerated and unlike the tricyclic antidepressants, has little to no anticholinergic effect [81]. Compared to Z-drugs, trazodone has a relatively longer half-life at 5-9 h, so daytime sedation is a potential side effect [81]. Despite trazodone's usage, there are no clinical trials on trazodone for insomnia treatment in the TBI population. For insomnia in the general population, trazodone increased sleep duration compared to placebo and in patients with comorbid depression was also found to increase total sleep time [78]. As depression is a common comorbidity in patients with TBI, trazodone may be first line for select patients.

\subsection{Melatonin/Melatonin Agonists}

Melatonin is a hormone synthesized in the pineal gland that is triggered by the absence of light and plays a crucial role in the sleep-wake cycle. As mentioned, TBI patients tend to have disruptions in the melatonin pathways, which result in lower melatonin levels later in the day compared to healthy controls [16]. A RCT comparing the efficacy of melatonin supplementation to placebo for TBI patients 
with sleep disturbance found improved sleep quality, sleep efficiency, and decreased anxiety with no significant difference in sleep latency [82].

Efficacy of exogenous melatonin has led to the development of melatonin agonist ramelteon. Similar to melatonin supplementation, ramelteon has a superior side effect profile [78]. In a pilot study investigating the effects of ramelteon on sleep among patients with TBI, patients were given $8 \mathrm{mg}$ nightly over 3 weeks. The study demonstrated a significant increase in total sleep time and a modest improvement in sleep latency compared to placebo. On standardized neuropsychological testing, participants also had improved scores particularly in executive functioning [83]. Currently, no generic formulation is commercially available so as melatonin agonists increase in popularity, they may become more affordable and viable options.

\section{Summary and Conclusions}

Insomnia is a highly prevalent and debilitating condition within the mTBI population with around $40 \%-65 \%$ of patients reporting symptoms of insomnia. As both mTBI and associated insomnia are underdiagnosed, a proper history and high clinical suspicion are important in detecting underlying sleep disorder. Although most patients with mTBI return to normal functioning, sleep disturbance is a subtle and often persistent condition lasting many years for a significant proportion of patients. Since many brain injury patients self-treat and feel lost when addressing these new sleep disturbances, it is important for providers to follow up with patients regarding sleep post-TBI and maintain a low threshold to intervene as poor sleep hinders recovery and social reintegration. When addressing impaired sleep, rule out common comorbidities prior to management as treatment may differ. Pharmacologic options are effective for situational use but may have negative consequences in the long term. As sleep impairment may last years after injury, attempting nonpharmacologic treatments such as sleep hygiene counseling and CBT are preferred as they demonstrate persistent benefits. Since mild TBI is by far the most common severity of TBI and data suggests that milder brain injury increases risk of insomnia, more research is needed towards studying insomnia and its treatment within the mild traumatic brain injury population.

Funding: This research received no external funding.

Acknowledgments: We want to thank Rutgers Robert Wood Johnson Medical School and JFK Johnson Rehabilitation Institute for allowing us to do this work. We would also like to thank our peers and friends for providing support and advice along the way.

Conflicts of Interest: The authors declare no conflict of interest.

\section{References}

1. Taylor, C.A.; Bell, J.M.; Breiding, M.J.; Xu, L. Traumatic Brain Injury-Related Emergency Department Visits, Hospitalizations, and Deaths-United States, 2007 and 2013. MMWR Surveill. Summ. 2017, 66, 1-16. [CrossRef]

2. Cassidy, J.D.; Carroll, L.J.; Peloso, P.M.; Borg, J.; von Holst, H.; Holm, L.; Kraus, J.; Coronado, V. Incidence, risk factors and prevention of mild traumatic brain injury: Results of the WHO Collaborating Centre Task Force on Mild Traumatic Brain Injury. J. Rehabil. Med. 2004, 36, 28-60. [CrossRef]

3. Powell, J.M.; Ferraro, J.V.; Dikmen, S.S.; Temkin, N.R.; Bell, K.R. Accuracy of mild traumatic brain injury diagnosis. Arch. Phys. Med. Rehabil. 2008, 89, 1550-1555. [CrossRef]

4. Wickwire, E.M.; Williams, S.G.; Roth, T.; Capaldi, V.F.; Jaffe, M.; Moline, M.; Motamedi, G.K.; Morgan, G.W.; Mysliwiec, V.; Germain, A.; et al. Sleep, Sleep Disorders, and Mild Traumatic Brain Injury. What We Know and What We Need to Know: Findings from a National Working Group. Neurotherapeutics 2016, 13, $403-417$. [CrossRef]

5. Mollayeva, T.; Mollayeva, S.; Colantonio, A. The Risk of Sleep Disorder among Persons with Mild Traumatic Brain Injury. Curr. Neurol. Neurosci. Rep. 2016, 16, 55. [CrossRef]

6. Vermaelen, J.; Greiffenstein, P.; deBoisblanc, B.P. Sleep in traumatic brain injury. Crit. Care Clinic. 2015, 31, 551-561. [CrossRef] 
7. Kraus, M.F.; Susmaras, T.; Caughlin, B.P.; Walker, C.J.; Sweeney, J.A.; Little, D.M. White matter integrity and cognition in chronic traumatic brain injury: A diffusion tensor imaging study. Brain 2007, 130, 2508-2519. [CrossRef]

8. Viola-Saltzman, M.; Watson, N.F. Traumatic Brain Injury and Sleep Disorders. Neurol. Clin. 2012, 30, $1299-1312$. [CrossRef]

9. Arciniegas, D.B.; Topkoff, J.; Silver, J.M. Neuropsychiatric aspects of traumatic brain injury. Curr. Treat. Options Neurol. 2000, 2, 169-186. [CrossRef]

10. Orff, H.J.; Ayalon, L.; Drummond, S.P. Traumatic brain injury and sleep disturbance: A review of current research. J. Head Trauma Rehabil. 2009, 24, 155-165. [CrossRef]

11. Viola-Saltzman, M.; Musleh, C. Traumatic brain injury-induced sleep disorders. Neuropsychiatr. Dis. Treat. 2016, 12, 339-348. [CrossRef]

12. Gilbert, K.S.; Kark, S.M.; Gehrman, P.; Bogdanova, Y. Sleep Disturbances, TBI and PTSD: Implications for Treatment and Recovery. Clin. Psychol. Rev. 2015, 40, 195-212. [CrossRef]

13. Yaeger, K.; Alhilali, L.; Fakhran, S. Evaluation of tentorial length and angle in sleep-wake disturbances after mild traumatic brain injury. Am. J. Roentgenol. 2014, 202, 614-618. [CrossRef]

14. Fakhran, S. Symptomatic white matter changes in mild traumatic brain injury resemble pathologic features of early alzheimer dementia. Radiology 2013, 269, 249-257. [CrossRef]

15. Hazra, A. Delayed thalamic astrocytosis and disrupted sleep-wake patterns in a preclinical model of traumatic brain injury. J. Neurosci Res. 2014, 92, 1434-1445. [CrossRef]

16. Shekleton, J.; Parcell, D.L.; Redman, J.R.; Phipps-Nelson, J.; Ponsford, J.L.; Rajaratnam, S.M.W. Sleep disturbance and melatonin levels following traumatic brain injury. Neurology 2010, 74, 1732-1738. [CrossRef]

17. Wilkinson, C.W.; Pagulayan, K.F.; Petrie, E.C.; Mayer, C.L.; Colasurdo, E.A.; Shofer, J.B.; Hart, K.L.; Hoff, D.; Tarabochia, M.A.; Peskind, E.R. High Prevalence of Chronic Pituitary and Target-Organ Hormone Abnormalities after Blast-Related Mild Traumatic Brain Injury. Front. Neurol. 2012, 3, 11. [CrossRef]

18. Zeitzer, J.M.; Friedman, L.; O'Hara, R. Insomnia in the context of traumatic brain injury. J. Rehabil. Res. Dev. 2009, 46, 827-836. [CrossRef]

19. Sabir, M.; Gaudreault, P.O.; Freyburger, M.; Massart, R.; Blanchet-Cohen, A.; Jaber, M.; Gosselin, N.; Mongrain, V. Impact of traumatic brain injury on sleep structure, electrocorticographic activity and transcriptome in mice. Brain Behav. Immun. 2015, 47, 118-130. [CrossRef]

20. Hong, C.T.; Wong, C.S.; Ma, H.P.; Wu, D.; Huang, Y.H.; Wu, C.C.; Lin, C.M.; Su, Y.K.; Liao, K.H.; Ou, J.C.; et al. PERIOD3 polymorphism is associated with sleep quality recovery after a mild traumatic brain injury. J. Neurol. Sci. 2015, 358, 385-389. [CrossRef]

21. El Shakankiry, H.M. Sleep physiology and sleep disorders in childhood. Nat. Sci. Sleep 2011, 3, 101-114. [CrossRef]

22. Schreiber, S.; Barkai, G.; Gur-Hartman, T.; Peles, E.; Tov, N.; Dolberg, O.T.; Pick, C.G. Long-lasting sleep patterns of adult patients with minor traumatic brain injury (mTBI) and non-mTBI subjects. Sleep Med. 2008, 9, 481-487. [CrossRef] [PubMed]

23. Lucke-Wold, B.P.; Smith, K.E.; Nguyen, L.; Turner, R.C.; Logsdon, A.F.; Jackson, G.J.; Huber, J.D.; Rosen, C.L.; Miller, D.B. Sleep disruption and the sequelae associated with traumatic brain injury. Neurosci. Biobehav. Rev. 2015, 55, 68-77. [CrossRef] [PubMed]

24. Kaufman, Y.; Tzischinsky, O.; Epstein, R.; Etzioni, A.; Lavie, P.; Pillar, G. Long-term sleep disturbances in adolescents after minor head injury. Pediatr. Neurol. 2001, 24, 129-134. [CrossRef]

25. Ouellet, M.C.; Morin, C.M. Subjective and objective measures of insomnia in the context of traumatic brain injury: A preliminary study. Sleep Med. 2006, 7, 486-497. [CrossRef] [PubMed]

26. Waldron-Perrine, B.; McGuire, A.P.; Spencer, R.J.; Drag, L.L.; Pangilinan, P.H.; Bieliauskas, L.A. The influence of sleep and mood on cognitive functioning among veterans being evaluated for mild traumatic brain injury. Mil. Med. 2012, 177, 1293-1301. [CrossRef] [PubMed]

27. Bolge, S.C.; Doan, J.F.; Kannan, H.; Baran, R.W. Association of insomnia with quality of life, work productivity, and activity impairment. Qual. Life Res. 2009, 18, 415-422. [CrossRef] [PubMed]

28. Mathias, J.; Alvaro, P. Prevalence of sleep disturbances, disorders and problems following traumatic brain injury: A meta-analysis. Sleep Med. 2017, 13, 898-905. [CrossRef] [PubMed]

29. Ouellet, M.C.; Beaulieu-Bonneau, S.; Morin, C.M. Insomnia in patients with traumatic brain injury: Frequency, characteristics, and risk factors. J. Head Trauma Rehabil. 2006, 21, 199-212. [CrossRef] [PubMed] 
30. Sullivan, K.A.; Berndt, S.L.; Edmed, S.L.; Smith, S.S.; Allan, A.C. Poor sleep predicts subacute postconcussion symptoms following mild traumatic brain injury. Appl. Neuropsychol. Adult 2016, 23, 426-435. [CrossRef]

31. Ouellet, M.C.; Savard, J.; Morin, C.M. Insomnia following Traumatic Brain Injury: A Review. Neurorehabil. Neural Repair 2004, 18, 187-198. [CrossRef] [PubMed]

32. Ohayon, M.M. Epidemiology of insomnia: What we know and what we still need to learn. Sleep Med. Rev. 2002, 6, 97-111. [CrossRef] [PubMed]

33. Fichtenberg, N.L.; Millis, S.R.; Mann, N.R.; Zafonte, R.D.; Millard, A.E. Factors associated with insomnia among post-acute traumatic brain injury survivors. Brain Inj. 2000, 14, 659-667. [CrossRef] [PubMed]

34. Tham, S.W.; Fales, J.; Palermo, T.M. Subjective and objective assessment of sleep in adolescents with mild traumatic brain injury. J. Neurotrauma 2015, 32, 847-852. [CrossRef] [PubMed]

35. Hu, T.; Hunt, C.; Ouchterlony, D. Is Age Associated With the Severity of Post-Mild Traumatic Brain Injury Symptoms? Can. J. Neurol. Sci. 2017, 44, 384-390. [CrossRef] [PubMed]

36. Petraglia, A.L.; Plog, B.A.; Dayawansa, S.; Chen, M.; Dashnaw, M.L.; Czerniecka, K.; Huang, J.H. The Spectrum of Neurobehavioral Sequelae after Repetitive Mild Traumatic Brain Injury: A Novel Mouse Model of Chronic Traumatic Encephalopathy. J. Neurotrauma 2014, 31, 1211-1224. [CrossRef] [PubMed]

37. Bryan, C.J. Repetitive traumatic brain injury (or concussion) increases severity of sleep disturbance among deployed military personnel. Sleep 2013, 36, 941-946. [CrossRef] [PubMed]

38. McKee, A.C.; Robinson, M.E. Military-related traumatic brain injury and neurodegeneration. Alzheimers Dement. 2014, 10, 242-253. [CrossRef] [PubMed]

39. Hicks, R.R.; Fertig, S.J.; Desrocher, R.E.; Koroshetz, W.J.; Pancrazio, J.J. Neurological effects of blast injury. J. Trauma 2010, 68, 1257-1263. [CrossRef] [PubMed]

40. Sayer, N.A.; Chiros, C.E.; Sigford, B.; Scott, S.; Clothier, B.; Pickett, T.; Lew, H.L. Characteristics and Rehabilitation Outcomes among Patients with Blast and Other Injuries Sustained During the Global War on Terror. Arch. Phys. Med. Rehabil. 2008, 89, 163-170. [CrossRef]

41. Linton, S.J.; Bryngelsson, I.L. Insomnia and its relationship to work and health in a working-age population. J. Occup. Rehabil. 2000, 10, 169-183. [CrossRef]

42. Baumann, C.R.; Werth, E.; Stocker, R.; Ludwig, S.; Bassetti, C.L. Sleep-wake disturbances 6 months after traumatic brain injury: A prospective study. Brain 2007, 130, 1873-1883. [CrossRef]

43. Farrell-Carnahan, L.; Barnett, S.; Lamberty, G.; Hammond, F.M.; Kretzmer, T.S.; Franke, L.M.; Geiss, M.; Howe, L.; Nakase-Richardson, R. Insomnia symptoms and behavioural health symptoms in veterans 1 year after traumatic brain injury. Brain Inj. 2015, 29, 1400-1408. [CrossRef] [PubMed]

44. Losoi, H.; Silverberg, N.D.; Wäljas, M.; Turunen, S.; Rosti-Otajärvi, E.; Helminen, M.; Luoto, T.M.; Julkunen, J.; Öhman, J.; Iverson, G.L. Recovery from Mild Traumatic Brain Injury in Previously Healthy Adults. J. Neurotrauma 2016, 33, 766-776. [CrossRef] [PubMed]

45. McMahon, P.J.; Hricik, A.; Yue, J.K.; Puccio, A.M.; Inoue, T.; Lingsma, H.F.; Vassar, M.J. Symptomatology and functional outcome in mild traumatic brain injury: Results from the prospective TRACK-TBI study. J. Neurotrauma 2014, 31, 26-33. [CrossRef]

46. Ma, H.P.; Ou, J.C.; Yeh, C.T.; Wu, D.; Tsai, S.H.; Chiu, W.T.; Hu, C.J. Recovery from sleep disturbance precedes that of depression and anxiety following mild traumatic brain injury: A 6-week follow-up study. BMJ Open 2014, 4. [CrossRef] [PubMed]

47. Martindale, S.L.; Farrell-Carnahan, L.V.; Ulmer, C.S.; Kimbrel, N.A.; McDonald, S.D.; Rowland, J.A. VA Mid-Atlantic MIRECC Registry Workgroup. Sleep Quality in Returning Veterans: The Influence of Mild Traumatic Brain Injury. Rehabil. Psychol. 2017, 62, 563-570. [CrossRef]

48. Theadom, A.; Starkey, N.; Jones, K.; Cropley, M.; Parmar, P.; Barker-Collo, S.; Feigin, V.L. Sleep difficulties and their impact on recovery following mild traumatic brain injury in children. Brain Inj. 2016, 30, 1243-1248. [CrossRef] [PubMed]

49. Pillar, G.; Averbooch, E.; Katz, N.; Peled, N.; Kaufman, Y.; Shahar, E. Prevalence and risk of sleep disturbances in adolescents after minor head injury. Pediatr. Neurol. 2003, 29, 131-135. [CrossRef]

50. Theadom, A.; Parag, V.; Dowell, T.; McPherson, K.; Starkey, N.; Barker-Collo, S.; Jones, K.; Ameratunga, S.; Feigin, V.L. Persistent problems 1 year after mild traumatic brain injury: A longitudinal population study in New Zealand. Br. J. Gen. Pract. 2015, 66, 16-23. [CrossRef] 
51. Duclos, C.; Beauregard, M.P.; Bottari, C.; Ouellet, M.C.; Gosselin, N. The impact of poor sleep on cognition and activities of daily living after traumatic brain injury: A review. Aust. Occup. Ther. J. 2015, 62, 2-12. [CrossRef] [PubMed]

52. Theadom, A.; Cropley, M.; Parmar, P.; Barker-Collo, S.; Starkey, N.; Jones, K.; Feigin, V.L. BIONIC Research Group. Sleep difficulties one year following mild traumatic brain injury in a population-based study. Sleep Med. 2015, 16, 926-932. [CrossRef] [PubMed]

53. Bonneau, S.B.; Ouellet, M.C. Fatigue in the first year after traumatic brain injury: Course, relationship with injury severity, and correlates. Neuropsychol. Rehabil. 2017, 27, 983-1001. [CrossRef] [PubMed]

54. Wylie, G.R.; Flashman, L.A. Understanding the interplay between mild traumatic brain injury and cognitive fatigue: Models and treatments. Concussion 2017, 2, 50. [CrossRef] [PubMed]

55. Norre, J.; Heitger, M.; Leathem, J.; Anderson, T.; Jones, R.; Flett, R. Mild traumatic brain injury and fatigue: A prospective longitudinal study. Brain Inj. 2010, 24, 1528-1538. [CrossRef] [PubMed]

56. Stulemeijer, M.; van der Werf, S.; Bleijenberg, G.; Biert, J.; Brauer, J.; Vos, P. Recovery from mild traumatic brain injury: A focus on fatigue. J. Neurol. 2006, 253, 1041-1047. [CrossRef] [PubMed]

57. Albicini, M.S.; Lee, J.; McKinlay, A. Ongoing daytime behavioural problems in university students following childhood mild traumatic brain injury. Int. J. Rehabil. Res. 2016, 39, 77-83. [CrossRef]

58. Mollayeva, T.; Pratt, B.; Mollayeva, S.; Shapiro, C.M.; Cassidy, J.D.; Colantonio, A. The relationship between insomnia and disability in workers with mild traumatic brain injury/concussion: Insomnia and disability in chronic mild traumatic brain injury. Sleep Med. 2016, 20, 157-166. [CrossRef]

59. Lavigne, G.; Khoury, S.; Chauny, J.M.; Desautels, A. Pain and sleep in post-concussion/mild traumatic brain injury. Pain 2015, 156, 75-85. [CrossRef]

60. Suzuki, Y.; Khoury, S.; El-Khatib, H.; Chauny, J.M.; Paquet, J.; Giguère, J.F.; Denis, R.; Gosselin, N.; Lavigne, G.J.; Arbour, C. Individuals with pain need more sleep in the early stage of mild traumatic brain injury. Sleep Med. 2017, 33, 36-42. [CrossRef]

61. MacGregor, A.J.; Dougherty, A.L.; Tang, J.J.; Galarneau, M.R. Postconcussive symptom reporting among US combat veterans with mild traumatic brain injury from Operation Iraqi Freedom. J. Head Trauma Rehabil. 2013, 28, 59-67. [CrossRef] [PubMed]

62. Sherman, K.B.; Goldberg, M.; Bell, K.R. Traumatic Brain Injury and Pain. Phys. Med. Rehabil. Clin. N. Am. 2006, 17, 473-490. [CrossRef] [PubMed]

63. Sandsmark, D.K.; Elliott, J.E.; Lim, M.M. Sleep-Wake Disturbances after Traumatic Brain Injury: Synthesis of Human and Animal Studies. Sleep 2017, 40. [CrossRef] [PubMed]

64. Tregear, S.; Reston, J.; Schoelles, K.; Phillips, B. Obstructive sleep apnea and risk of motor vehicle crash: Systematic review and meta-analysis. J. Clin. Sleep Med. 2009, 5, 573-581. [PubMed]

65. Howlett, J.R.; Stein, M.B. Post-Traumatic Stress Disorder: Relationship to Traumatic Brain Injury and Approach to Treatment. In Translation Research in Traumatic Brain Injury (Frontiers in Neuroscience), 1st ed.; Laskowitz, D., Grant, G., Eds.; CRC Press/Taylor and Francis Group: Boca Raton, FL, USA, 2016; Volume 57, Chapter 16; ISBN 978-1-4665-8491-4.

66. Tanev, K.S.; Pentel, K.Z.; Kredlow, M.A.; Chamey, M.E. PTSD and TBI co-morbidity: Scope, clinical presentation and treatment options. Brain Inj. 2014, 28, 261-270. [CrossRef] [PubMed]

67. Capaldi, V.F.; Guerrero, M.L.; Killgore, W.D. Sleep disruptions among returning combat veterans from Iraq and Afghanistan. Mil. Med. 2011, 176, 879-888. [CrossRef]

68. Ayalon, L.; Borodkin, K.; Dishon, L.; Kanety, H.; Dagan, Y. Circadian rhythm sleep disorders following mild traumatic brain injury. Neurology 2007, 68, 1136-1140. [CrossRef]

69. Roth, T. Prevalence, associated risks, and treatment patterns of insomnia. J. Clin. Psychiatry 2005, 6, 10-13.

70. Capaldi, V.F.; Kim, J.R.; Grillakis, A.A.; Taylor, M.R.; York, C.M. Insomnia in the Military: Application and Effectiveness of Cognitive and Pharmacologic Therapies. Curr. Psychiatry Rep. 2015, 17, 85. [CrossRef]

71. Blinman, T.A.; Houseknecht, E.; Snyder, C.; Wiebe, D.J.; Nance, M.L. Postconcussive symptoms in hospitalized pediatric patients after mild traumatic brain injury. J. Pediatr. Surg. 2009, 44, 1223-1228. [CrossRef]

72. Bogdanov, S.; Naismith, S.; Lah, S. Sleep outcomes following sleep-hygiene-related interventions for individuals with traumatic brain injury: A systematic review. Brain Inj. 2017, 31, 422-433. [CrossRef] [PubMed]

73. Ouellet, M.C.; Morin, C.M. Efficacy of cognitive-behavioral therapy for insomnia associated with traumatic brain injury: A single-case experimental design. Arch. Phys. Med. Rehabil. 2007, 88, 1581-1592. [CrossRef] [PubMed] 
74. Nguyen, S.; McKay, A.; Wong, D.; Rajaratnam, S.M.; Spitz, G.; Williams, G.; Mansfield, D.; Ponsford, J.L. Cognitive Behavior Therapy to Treat Sleep Disturbance and Fatigue After Traumatic Brain Injury: A Pilot Randomized Controlled Trial. Arch. Phys. Med. Rehabil. 2017, 98, 1508-1517. [CrossRef] [PubMed]

75. Luik, A.I.; Kyle, S.D.; Espie, C.A. Digital Cognitive Behavioral Therapy (dCBT) for Insomnia: A State-of-the-Science Review. Curr. Sleep Med. Rep. 2017, 3, 48-56. [CrossRef] [PubMed]

76. Espie, C.A.; Luik, A.I.; Cape, J.; Drake, C.L.; Siriwardena, A.N.; Ong, J.C.; Gordon, C.; Bostock, S.; Bostock, S.; Hames, P.; et al. Digital Cognitive Behavioural Therapy for Insomnia versus sleep hygiene education: The impact of improved sleep on functional health, quality of life and psychological well-being. Study protocol for a randomised controlled trial. Trials 2016, 17, 257. [CrossRef]

77. Sirdifield, C.; Chipchase, S.Y.; Owen, S.; Siriwardena, A.N. A Systematic Review and Meta-Synthesis of Patients' Experiences and Perceptions of Seeking and Using Benzodiazepines and Z-Drugs: Towards Safer Prescribing. Patient 2017, 10, 1-15. [CrossRef] [PubMed]

78. Larson, E.B.; Zollman, F.S. The effect of sleep medications on cognitive recovery from traumatic brain injury. J. Head Trauma Rehabil. 2010, 25, 61-67. [CrossRef]

79. Hajak, G.; Muller, W.E.; Wittchen, H.U.; Pittrow, D.; Kirch, W. Abuse and dependence potential for the non-benzodiazepine hypnotics zolpidem and zopiclone: A review of case reports and epidemiological data. Addiction 2003, 98, 1371-1378. [CrossRef]

80. Li Pi Shan, R.S.; Ashworth, N.L. Comparison of lorazapam and zopicloine for insomnia in patients with stroke and brain injury. Am. J. Phys. Med. Rehabil. 2004, 83, 421-427. [CrossRef]

81. Glenn, M.B.; Wroblewski, B. Twenty years of pharmacology. J. Head Trauma Rehabil. 2005, 20, 51-61. [CrossRef]

82. Grima, N.A.; Rajaratam, S.M.W.; Mansfield, D.; Sletten, T.L.; Spitz, G.; Ponsford, J.L. Efficacy of melatonin for sleep disturbance following traumatic brain injury: A randomized controlled trial. BMC Med. 2018, 16, 8. [CrossRef] [PubMed]

83. Leguerica, A.; Jasey, N.; Portelli Tremont, J.N.; Chiaravalloti, N.D. Pilot study on the effect of ramelteon on sleep disturbance after traumatic brain injury: Preliminary evidence from a clinical trial. Arch. Phys. Med. Rehabil. 2015, 96, 1802-1809. [CrossRef] [PubMed] 